\title{
OBJETIVIDADE HISTÓRICA NO MANUAL DE TEORIA DA HISTÓRIA DE ROBERTO PIRAGIBE DA FONSECA (1903-1986)
}

\author{
ITAMAR FREITAS \\ Universidade Federal de Sergipe \\ Aracajú | Sergipe | Brasil \\ itamarfreitasufs@gmail.com \\ orcid.org/0000-0002-2226-2015
}

Neste artigo, tratamos das ideias de "Teoria da História" e de "objetividade", veiculadas no impresso propedêutico Manual de Teoria da História, produzido no ambiente da Faculdade de Filosofia da Pontifícia Universidade Católica do Rio de Janeiro, por Roberto Piragibe da Fonseca, entre 1943 e 1967. O professor de Propedêutica entendia Teoria da História como um construto de Metafísica e Lógica. Com o Manual, Fonseca queria legitimar a cientificidade do discurso do historiador e do professor de História e instrumentalizá-los para combater o materialismo e o ateísmo no Brasil, tanto nas universidades como nas escolas do ensino secundário. O resultado dessa composição em termos de objetividade do conhecimento histórico foi a ideia de que a cientificidade do trabalho do historiador e do professor de História do curso superior seria garantida por meio de uma série de critérios de validação normativa e operacional que consideravam o respeito às leis metafísicas, morais e físicas, empregadas sob diferentes pesos no trabalho de constatação, interpretação e exposição dos fatos.

objetividade - metodologia da história ensino de história - manual de teoria da história 


\title{
HISTORICAL OBJECTIVITY IN MANUAL OF THEORY OF THE HISTORY BY ROBERTO PIRAGIBE DA FONSECA (1903-1986)
}

\author{
ITAMAR FREITAS \\ Universidade Federal de Sergipe \\ Aracajú | Sergipe | Brazil \\ itamarfreitasufs@gmail.com \\ orcid.org/0000-0002-2226-2015
}

In this paper we deal with "Theory of History" and "objectivity" ideas, transmitted in the propaedeutic written entitled Manual of Theory of the History and produced in College of Philosophy of Pontifícia Universidade Católica do Rio de Janeiro ambience by Boberto Piragibe da Fonseca, between 1943 and 1967. The professor of Propaedeutics class understood "Theory of History" as a construct of Metaphysic and Logic. With the Manual, Fonseca intended to legitimize the scientificity of discourse of historian and of history professor and make them a tool to intervene in order to combat the materialism and atheism in Brazil, in universities as well in high schools. The result this composition in term of historical knowledge objectivity was the idea that the works scientificity of historians and History professor in higher education would be ensured through a series of criteria of normative and operational validation. Such criteria took into account the respect to metaphysical, moral and physical laws, used according different weights in work validation, interpretation and exposition of facts.

objectivity - history methodology bistory teaching - theory of history manual 


\section{INTRODUÇÃO}

De modo instrumental, podemos definir o substantivo "objetividade" como o caráter de ser ou de existir do objeto e o caráter de ser conhecido do "objeto", este entendido como uma ideia ou coisa situada em frente ou na mente do sujeito conhecedor. René Descartes (1596-1650) e Immanuel Kant (17241804), dois dos filósofos mais citados pelos escritores de manuais de Teoria da História e de Metodologia da História no período de 1870-1940, concordariam com essa definição genérica de objeto. Apesar das distâncias entre as abordagens inatista e crítica que professavam sobre o conhecer, Descartes e Kant referiramse aos objetos do conhecimento de maneira espacializada (objetos internos e externos do conhecedor) e discutiram modalidades de correspondência entre ideias e coisas.

Com o termo "objetividade", porém, o exercício contrafactual não se sustenta. A expressão mais próxima de uma objetividade científica intermediada pelo Discurso do método (1637) e pelas Meditações (1641) de Descartes - o "poder de julgar de forma correta e discernir entre o verdadeiro e o falso" (Descartes 1999a, 35) - seria a formação de ideias claras e distintas (Descartes 1999b, 242) ou a demolição de toda opinião suscetível à dúvida. Objetividade, então, poderia ser traduzido por indubitabilidade. Descartes até emprega "realidade objetiva" e realidade encontrável "objetivamente em suas causas" para comunicar a supremacia das ideias produzidas pelo entendimento sobre as ideias provenientes dos sentidos (Descartes 1999b, 275), ou para caracterizar a coisa ou o conceito "imediatamente representado por meio da concepção" (Cottingham 1993, 137).

As derivações do termo, porém, estariam bem distantes daquelas empregadas por Kant, na Crítica da rąão pura (1781/1787), onde o objeto era algo não contido exclusivamente no sujeito, ou seja, situado exteriormente ao sujeito, embora não puramente empírico. Objeto era "matéria", "fenômeno" e "forma". Esses três conceitos correspondiam aos meios de conhecimento ou às operações cognitivas e estéticas conjugadas que o filósofo apresentou como alternativa aos céticos e aos dogmáticos em teoria do conhecimento: recepção/sensibilidade (da matéria), intuição empírica (do fenômeno) e pensamento apriorístico (mediante a forma) (Kant 2013, 71). "Validade objetiva", expressão mais próxima de uma objetividade científica mediada pelo método do idealismo transcendental, seria, então, o caráter do conhecimento cujo "pensamento, mediante as intuições puras de espaço e tempo, é aplicado a um objeto apresentado fenomenologicamente". Um saber objetivo (um tipo de assentimento), por seu turno, é "aquele racionalmente válido para todos os pensantes - diferentemente da fé, que é validada racionalmente apenas por um praticante" (Kant 2013, 137, 593).

Essa objetividade, como definida por Kant, foi "criativamente adaptada" - por erro de interpretação, preocupações disciplinares, filosofias locais ou interesses individuais - e passou a ser parâmetro de mensuração da cientificidade entre os físicos, fisiologistas e botânicos na segunda metade do século XIX (Daston; Galison 2007, 206-208). Foram eles os tradutores do caráter de ser objetivo como capacidade de apagamento do self de quem se propunha a conhecer, isto é, como a resultante de uma luta entre a vontade e o Eu não pensada originalmente por Kant (ocupado, nessa passagem, com epistemologia e não com psicologia). Correlatamente, essa datação cronológica marcaria o nascimento do self cientista, como registram Lorraine Daston e Peter Galison (2007, 205-210). 
Antes de os trabalhos de Daston e Galison virem a público, essa compreensão mecânica de objetividade (embora de modo não hegemônico) já habitava a mente de muitos leitores da historiografia e de parte dos historiadores que escreviam manuais propedêuticos de História da Historiografia, Metodologia e Teoria da História. Somada à crítica sobre a impossibilidade de conhecer "a coisa em si", que gerou uma rotação na díade objetivo/subjetivo, desde o assentimento geral ou particular da proposição, até a disposição interna ou externa ao sujeito, foi (e ainda é) comum qualificar, dividir e reduzir os historiadores e os seus trabalhos em objetivos e subjetivos, sob díades simplificadoras, a exemplo de: imparciais e engajados, positivistas e críticos, documentados e panfletários e, correlatamente, profissionais e amadores.

$\mathrm{Na}$ crítica a esse senso comum, Artur Assis não apenas combate a tese de que o "outro" da objetividade do historiador seria a sua subjetividade (o outro é a mentira), como também critica a adoção direta das classes de objetividade formuladas por Daston e Galison (verdade-natureza, objetividade mecânica e julgamento treinado). Apesar de originais na historicização do ethos cientista, esses tipos não serviriam como designadores de períodos e modelos para a história da identidade profissional do historiador porque a segunda metade do século XIX está repleta de casos de compatibilização de princípios e práticas de subjetividade (a visão perspectivada - nacionalista, localista, religiosa, partidária etc.) com a adoção de princípios e práticas de objetividade (crítica de fontes empregadas para controlar possíveis vícios da testemunha e do historiador) (Assis 2016, 19). Em outros termos, a objetividade perseguida por historiadores não significaria, necessariamente, o esforço e a prática da extinção da subjetividade, uma vez que essa subjetividade era necessária e, paradoxalmente, um meio garantidor de objetividade.

A posição de Assis (2016) reforça, indiretamente, as assertivas de Allan Megill que situa os debates sobre objetividade histórica em Johann Gustav Droysen (1808-1884) como marco da emergência de teorias e metodologias da história referentes ao período entre 1870 e 1940, na Europa e na América, fundamentadas em questões morais e questões epistêmicas (Megill 2013, 12-13). Megill refere-se, entre casos destacados, ao trabalho do estadunidense Charles Beard (1874-1948), que concebia a objetividade como fim mediado por instrumentos de "crítica, autenticação e verificação" (para minimizar as insuficiências do material), escolhas do historiador assumidamente interessadas, em termos sociais, políticos, econômicos, étnicos e de gênero, e informação ao leitor sobre as limitações do trabalho do historiador (para justificar a interferência dos valores) (Beard 2013, 340, 350-353). Tratava-se, portanto, da mesma argumentação usada por Ernst Bernheim (1850-1942) para descrever o seu ideal de objetividade histórica, décadas antes da publicação do discurso de Beard (Bernheim 1903, 716-717).

Ao exemplo de Beard podemos acrescentar a passagem de Robin George Collingwood (1899-1943) que definia a objetividade como a capacidade de o historiador pensar por si mesmo o pensamento do autor-objeto de estudo. Para o professor inglês, a objetividade dependeria da autonomia do historiador ao fazer boas perguntas, selecionar os depoimentos que lhe servissem, apresentar as respostas que ele sentisse ser as mais corretas e no tempo que achasse conveniente (para justificar a interferência dos valores e dos princípios epistêmicos), mantendo, contudo, as atividades de crítica e de interpretação de fontes (para minimizar as insuficiências do material) (Collingwood 2004a, 335350). 
Mas nem só de práticas inglesas, estadunidenses e alemãs pode ser constituída a história da historiografia daquele período recortado por Megill, onde são fabricadas as primeiras obras de teoria da história (no sentido indicado pelo próprio Megill). Historiadores brasileiros também produziram discursos normativos a respeito dos quais não é tão fácil reduzir a discussão sobre as relações universalismo-particularismo ou psiquê-episteme à tipificação do texto ou do autor como pertencentes à "escola metódica" (supostamente mais objetivista), ao "marxismo" (supostamente mais subjetivista), associado às práticas de institutos históricos (ditas mais imparciais) ou próximas ao ethos universitário (visto como afeito à pluralidade de perspectivas), enfim, trabalhos que escapam à tipificação unívoca de filiados à filosofia especulativa ou ao método crítico, seu suposto contrário.

No período de 1880-1930, mais de 60 escritores refletiram sobre teoria da história, produzindo aproximadamente duas centenas de citações veiculadas na Revista do Instituto Histórico e Geográfico Brasileiro, sintetizáveis em duas frases que prescreviam e externalizavam princípios de objetividade, justificando socialmente a existência de um intelectual nomeado de "historiador": "Deixe o passado falar por si mesmo" e "Fale sobre o passado, empregando o método histórico" (Freitas 2015). Um desses autores, Francisco José de Oliveira Viana (1883-1951), ganhou monografia indiciariamente designada como $O$ charme da ciência e a sedução da objetividade (Bresciani 2005), dado o seu esforço por transformar a prática de construção de sínteses sobre história nacional com o emprego do método "naturalista", "não apriorístico", "objetivo" e realista (Bresciani 2005, 174-176).

Esses discursos do IHGB eram, contudo, pronunciados entre pares acadêmicos. Seus autores não possuíam pupilos, discípulos ou alunos no interior de um curso de Licenciatura em História, simplesmente porque tais cursos somente seriam criados em meados da década de 1930. É exatamente com esse outro tipo de discurso, mais recente e, paradoxalmente, mais raro, que nos ocupamos neste artigo. Aqui tratamos dos significados de Teoria da História e de objetividade histórica em uma brochura propedêutica efetivamente destinada aos alunos da disciplina "Introdução à História" (1943-1959), na Faculdade de Filosofia da Pontifícia Universidade Católica do Rio de Janeiro, e transformadas por seu autor, Roberto Piragibe da Fonseca, no Manual de Teoria da História, em 1960.

Tomando o impresso como centro (e exemplo), dissertamos sobre um particular momento da experiência nacional recente, onde Teoria da História, Metodologia da História, História da Historiografia e Introdução à História ainda não compunham os cursos superiores na condição de cadeiras. Aqui, questionamos, sobretudo: o que pode informar o Manual da Teoria da HistóriaMetafísica e Lógica da História sobre esse período marcado por uma iniciativa de profissionalização via institucionalização dos saberes teóricos da História em cursos de licenciatura em História no Brasil? Quais questões existenciais motivaram Piragibe da Fonseca a intitular o seu manual como Teoria da História e a atravessar o seu texto com a categoria da objetividade? Qual tipologia do nosso tempo explicaria melhor o sentido de objetividade partilhado/cunhado pelo professor carioca?

Nas próximas seções, tentamos responder a essas questões, examinando brevemente aquilo que os propedeutas da História pensavam ser a Teoria da História ensinável em um curso de Introdução à História entre as décadas de 40 e 50 do século passado. Em seguida, descrevemos e comentamos a ideia de Teoria da História disseminada pelo Manuale alguns de seus respectivos aportes 
de legitimação. $\mathrm{Na}$ terceira parte e nas conclusões, por fim, dissertamos sobre as relações que Piragibe da Fonseca estabeleceu entre Metafísica e Lógica para fundamentar as suas ideias de objetividade histórica.

\section{Roberto Piragibe da Fonseca E AS FINALIDADES DA PROPEDÊUTICA HISTÓRICA}

Roberto Piragibe da Fonseca é um ilustre desconhecido nos trabalhos produzidos nas últimas duas décadas sobre História da Historiografia brasileira. No campo do Direito, ao contrário, a literatura acadêmica explora as relações da família de Fonseca com Rui Barbosa, a avaliação dos seus livros de Direito e dos comentários sobre obras memorialistas que apresentou ou produziu. Por esses trabalhos, sabemos que a sua formação escolar (1923-1929) foi distribuída entre Maceió, Rio de Janeiro (Colégio Santo Inácio) e Rio Grande do Sul. Graduado em Direito pela Universidade do Rio de Janeiro, por lá se radicou como professor de Direito Internacional Público (1930). Além de atuar como titular em Direito na Faculdade de Ciências Econômicas (Barreto 1986; Codato; Guadalini Júnior 2003, 160), foi livre-docente da Faculdade Nacional de Direito da Universidade do Brasil e assumiu, na década de 1960, a chefia do curso de Filosofia da Pontifícia Universidade Católica do Rio de Janeiro (PUC-RIO).

Nosso autor era, talvez, um daqueles "virgens" polígrafos docentes de História, em termos de produção nas suas respectivas áreas de atuação - História Moderna, História Contemporânea, História da Civilização - denunciados por José Honório Rodrigues, nos anos 1970 (Rodrigues 1970, 37-38). Mas não podemos dizer algo semelhante quando os assuntos são o Direito e a Teoria da História, conhecimentos sobre os quais produziu livros de introdução: Breviário de Introdução à Ciência do Direito Positivo (1955) e Teoria da História - Metafísica e Lógica da História (1966).

Fonseca foi professor de Propedêutica da História na PUC-RJ, em 1943, sob a arguta interferência do Padre Jesuíta Leonel Edgard da Silveira Franca (1893-1948), uma aproximação ocorrida, provavelmente, ainda no Colégio Santo Inácio, onde Franca tornou-se professor e, depois, vice-reitor. $O$ próprio Fonseca ressalta que Franca, quando Reitor das Faculdades Católicas do Rio de Janeiro, abriu uma "Seção de Geografia e História na Faculdade de Filosofia", naquele mesmo ano de 1943. Desde então e, publicamente, a partir de 1955, nosso autor se regozija do pioneirismo católico na instituição do curso de "Propedêutica e metodologia da História", quando, institucionalmente, a primeira iniciativa do tipo, na Pontifícia Universidade Católica de São Paulo (PUC-SP), somente aconteceria na metade dos anos 1950, com as aulas do holandês José Van Den Besselaar (1906-2001) (Camargo Júnior 2016, 73). Na década anterior, portanto, Fonseca já cumpria a sua hora semanal de "propedêutica da História" e o mesmo tempo para "metodologia da História", destinadas aos alunos de Geografia e História, respectivamente, do segundo e terceiro anos (Fonseca 1953, 119-120). As preleções daquele curso extracurricular de 1943 foram publicadas na revista Verbum, em 1953 e, em 1956, surgiam como conteúdo da cadeira obrigatória para o curso de formação de professores, legitimada nacionalmente com a autonomização das graduações de História e Geografia (Fonseca 1967, 11).

Nessa disputa sobre a originalidade dos currículos de História e da ação pioneira de determinados professores, ele omite, contudo, a nomeação da cadeira de "Introdução Metodológica à História", instituída na Faculdade Nacional de Filosofia (FNFI) da Universidade do Brasil (1955), que manteve a 
orientação da missão francesa no sentido de criar um curso de "Pesquisas históricas e bibliografia" em 1935 (Ferreira 2013, 50-51). Também não cita a criação da disciplina "Introdução aos Estudos Históricos" no primeiro semestre de 1956 na Faculdade de Filosofia da Universidade de São Paulo (USP) (Roiz 2006, 90). Em 1959, quando sua Propedêutica é transformada em Teoria da História, ele também omite o impresso do mesmo gênero produzido por Francisco Isoldi (1879-1960) na Faculdade de Letras e Filosofia de São Paulo (1932) e o manual de José Honório Rodrigues, produzido a partir de cursos promovidos pelo Instituto Rio Branco (1946), embora o cite como referência sobre Metodologia da História.

Essa última omissão é mais significativa. Com o "esquecimento", muito provavelmente Fonseca demonstrava alguma espécie de "mágoa" em relação a Rodrigues. O conterrâneo - que fizera curso de Metodologia da História na Universidade de Columbia (1943-1944) (Rodrigues 1969,13) e se tornaria o mais produtivo especialista em História da Historiografia Brasileira até os anos 80 -, sugerira ao controverso Juraci Magalhães (1905-2001), ex-Tenente, senador pela Bahia e líder nacional da União Democrática Nacional (UDN) (Fundação Getúlio Vargas 2001), que apresentasse um projeto instituindo a "Metodologia da História" como "cadeira" obrigatória para os cursos de Geografia, História e Filosofia e facultativa para os cursos de Ciências Sociais e Pedagogia (Folha da Manhã 1955; Rodrigues 1970, 232).

O projeto de Lei do Senado n. 22, de 1955, provavelmente escrito pelo próprio Rodrigues, radicalizava a estruturação do currículo de GeografiaHistória, que possuía, em geral, desde 1939, cinco cadeiras focadas em conteúdo substantivo: História Antiga e Média, História Moderna, História Contemporânea, História do Brasil e História da América (Nascimento 2013, 276). A proposição era justificada pela experiência "universalmente aceita e louvada" e exemplificada com as práticas francesas, alemãs e estadunidenses, tanto para a melhoria do ensino superior como para a melhoria do ensino de História na escola secundária brasileira (Brasil 1955).

No mesmo ano, o projeto foi considerado inconstitucional porque "criava empregos em serviços existentes", uma competência reservada ao Presidente da República (Campos 1959, 1871). O senador Basílio Celestino tentou salvar a iniciativa, emendando o Projeto no sentido de que o Presidente enviasse mensagem ao Congresso Nacional, visando a criação da referida cadeira. Em abril de 1963, quando foi posto novamente em discussão, Magalhães não era mais senador e a Lei de Diretrizes e Bases da Educação Nacional já estava aprovada. Foi o bastante para que o senador Walfredo Gurgel, então relator, rejeitasse aquele projeto de Lei, deixando a cargo dos "Conselhos universitários" a responsabilidade de criá-la, no rol das "disciplinas complementares ou optativas" (Celestino 1959, 2108; Gurgel 1963, 567-568; Oliveira 2019, 95-96).

A sorte da cadeira, jogada entre o Executivo, o Legislativo e, novamente o Executivo (mediante ação dos agora autônomos professores universitários), pode, entretanto, esconder outro conflito: a própria noção de "teoria". Sabemos das preferências de Rodrigues pela "Metodologia" (Oliveira 2019, 89-100) e das suas reservas com relação à "Teoria da História" (Saad 2016), apesar de ele próprio ter designado um dos seus livros com essa expressão. Sabemos também da preferência de Fonseca pelas expressões "Propedêutica" da História e "Teoria da História" como matérias que justificariam a racionalidade da Ciência Histórica nos cursos de formação de professores. Curiosamente, é com as expressões "Propedêutica" e "Teoria da História" (com iniciais em maiúsculas) que o 
senador Gurgel vai construir o seu relatório, negando o pleito de Magalhães. Para Gurgel, "quando estudada em nível superior", a Teoria da História forneceria "o complexo de princípios gerais ou prolegômenos da história que proporcionam [...] um entendimento integral da marcha da humanidade no tempo e no espaço, com a responsabilidade de conceituar a história e de determinar o caráter científico, o sentido e a utilidade da história" (Gurgel 1963, 568). Em outros termos, a "teoria" do senador Magalhães e do professor Rodrigues era Filosofia Crítica (ou Epistemologia ou Metodologia) e a teoria do senador Gurgel e do professor Fonseca era filosofia especulativa da História (ou Metafísica da História).

Para Fonseca, a parte mais dolorosa do discurso de Gurgel era a afirmação de que "nada" existia "no país", naquele 1955:

\begin{abstract}
É claro que tal não significa descaridoso olvido votado a quem trabalha na sombra, sem intuitos de prejudicar quem quer que seja e sem propósitos de colher gloríolas pessoais. Trata-se, tão só, de carência de informação, mas de carência dificilmente explicável, pois não sabemos como pode ser ignorada de especialistas a atividade correlata de alguém [o próprio Fonseca] que milita à luz de publicidade inevitável, se bem que discreta, e em centro universitário dos mais categorizados e austeros, do Brasil e do Continente [a Faculdade de Filosofia da PUC-R]]. Com efeito, ao invés do que supõe o erudito relator do projeto legal em apreço, algo existe no país, e se faz muito, com referência à 'criação' agora planejada, e mesmo bastante mais do que se almeja 'criar' através dêsse ato legislativo.

(Fonseca 1959, 268-269).
\end{abstract}

Fonseca até poderia considerar a PUC-RJ "a pioneira incontestável, no Brasil, do ensino da Teoria da História" (Fonseca 1967, 11-12), mas a "cadeira" institucionalizada pelo Estado foi mesmo a de "metodologia", prescrita pelo senador. Fora, finalmente, integrada ao "currículo mínimo do curso de História", sob a via apontada por Gurgel, ou seja, mediante parecer do Conselho Federal de Educação (CFE) naquele ano de 1963. Quanto à "teoria", permaneceria na condição de conteúdo substantivo da "Introdução aos estudos históricos" até 1970 (Esponsel 1970, 220; Lacombe, 1972, 193; Rodrigues 1970, 232, 234). Nos congressos da Sociedade Brasileira de Pesquisa Científica (SBPC), há indício dessa trajetória vitoriosa. Foram as "Questões de Metodologia da História" (e não de teoria), por sua vez, que inauguraram a criação da seção "Ciências Humanas (Linguística e História) em 1973. (Folha de São Paulo, 10 jul. 1973; 23 abr. 1974).

O pioneirismo reclamado por Fonseca com relação ao curso (que introduz as disciplinas "Teoria" e "Introdução") foi reconhecido no II Encontro Brasileiro sobre Introdução ao Estudo da História (1970), ocorrido na Universidade de Juiz de Fora. Fonseca ganhou, enfim, a homenagem dos seus pares. Mas, a iniciativa tratar-se-ia, talvez, de uma corrigenda, já que o nome de Piragibe sequer constava nos Anais daquele primeiro Encontro (I EBIEH, Nova Friburgo-RJ, 7-3/07/1968), onde brilhara José Honório Rodrigues.

A ação de Rodrigues, injustiçado entre os professores universitários do Rio de Janeiro e também de São Paulo (Rodrigues 1969, 438) - por não ver a metodologia, a teoria e a historiografia introduzidas como "cadeiras" nos cursos de História desde 1946 (que lhe possibilitaria, inclusive, o acesso a um emprego universitário) -, de certa forma, nos estimula a entender a ironia de Fonseca ao comentar o texto de Juracy Magalhães: Rodrigues, reconhecido produtor de propedêuticas historiográficas com cores brasileiras, não citou Fonseca na terceira edição da sua Teoria da História do Brasil (1969) e, ainda, nas contribuições 
que dera aos Anais do I EBIEH (1970) sobre a história das disciplinas teóricometodológicas de História no Brasil.

Naquele lampejo de ego (criticando o senador Magalhães), contudo, Fonseca talvez não explicasse os principais motivos que o levaram a se interessar em publicar impressos propedêuticos e empenhar-se na disseminação de critérios de objetividade histórica para os profissionais que faziam uso da escrita da História. Fonseca trabalhou em três frentes dos domínios teóricos da formação de professor de História: a abrangente "Propedêutica" (introdução), a mais restrita e abstrata "Teoria" (Filosofia especulativa) e a "Metodologia". Com o "Programa e breviário de propedêutica e de metodologia da história", publicado esparsamente na revista católica Verbum (1953/1959), ele se dirigiu aos alunos do curso de Geografia e História (somente desmembrado em 1955). Com o Manual de Teoria da História, ele planejava se projetar diante dos graduandos de "História, Filosofia, Didática e Jornalismo", que frequentavam as faculdades de Filosofia. Com ambos, poderia falar à exígua classe média do Distrito Federal - advogados, artistas, jornalistas e professores do ensino secundário -, exercitando sua militância em prol do catolicismo sob bases agostinianas:

\footnotetext{
Não que o professor responsável [Fonseca], naturalmente católico, ortodoxo e militante, - ainda alimente dúvidas a respeito e, portanto, ainda peça luzes ao livre debate de opiniões. Mas como a filosofia católica da história, - e, desgraçadamente os mesmos Mandamentos divinos -, segue sofrendo a impugnação maliciosa e pedante do mundo obstinado em não crer, torna-se dever inconcusso do magistério confessional submeter a tese, honesta e documentadamente, já que fundada nos postulados assentes no De Civitate Dei, ao exame e apreciação dos que, animados de boa-fé, estudam o problema filosófico da história.

Fá-lo, porém, o professor responsável, é claro, sem temer contraditas, e sobretudo, sem admitir possíveis e pessoais câmbios de rumo, mas apenas, - seja tolerado o símile -, como o apologeta que, serena e inabalavelmente confiante na Verdade a que se arrima, desenvolve ante o ouvinte a exposição raciocinada dos fundamentos da Fé com o propósito único e exclusivo de iluminar e converter. (Fonseca 1959, 202-203. Grifos nossos).
}

Como vemos, a propedêutica histórica era instrumento de combate à descrença e mecanismo de conversão. Na atividade didática, contudo, Fonseca anunciava o aprendizado de princípios e práticas da ciência Histórica como uma defesa da História-ciência frente aos que a consideravam atividade produtora de "conhecimentos ornamentais" e aos que a entendiam, radicalmente, como "mestra da vida", "narrativa sem pé nem cabeça" ou "supina inutilidade" (Fonseca 1967, 17-19). Quais seriam, então, os atributos a conservar entre os professores, alunos e historiadores que defenderiam a História-ciência de impropérios desse tipo? Quais argumentos uma anunciada teoria da História de concepção católica emprestaria ao discurso sobre objetividade histórica empregado por Fonseca? Para o fornecimento dessas respostas, acompanhemos uma descrição contextualizada do seu manual, com foco nas matérias estruturantes da sua Teoria. 


\section{A TEORIA Da HistóRIA COMO COMPOSIÇÃo DE LógiCa E METAFísica}

O Manual de Piragibe da Fonseca seguiu a arquitetura da informação dos impressos propedêuticos que circulavam entre meados do século XIX e o primeiro quarto do século XX, principalmente, na Europa e na América. Os modos de organizar os dados (sumários por capítulo, bibliografia comentada por seções, listas e esquemas sinópticos e indicações de traduções no vernáculo) eram semelhantes aos empregados pelos renomados manuais de E. Bernheim, W. Bauer, C.-V. Langlois, C. Seignobos e F. M. Fling.

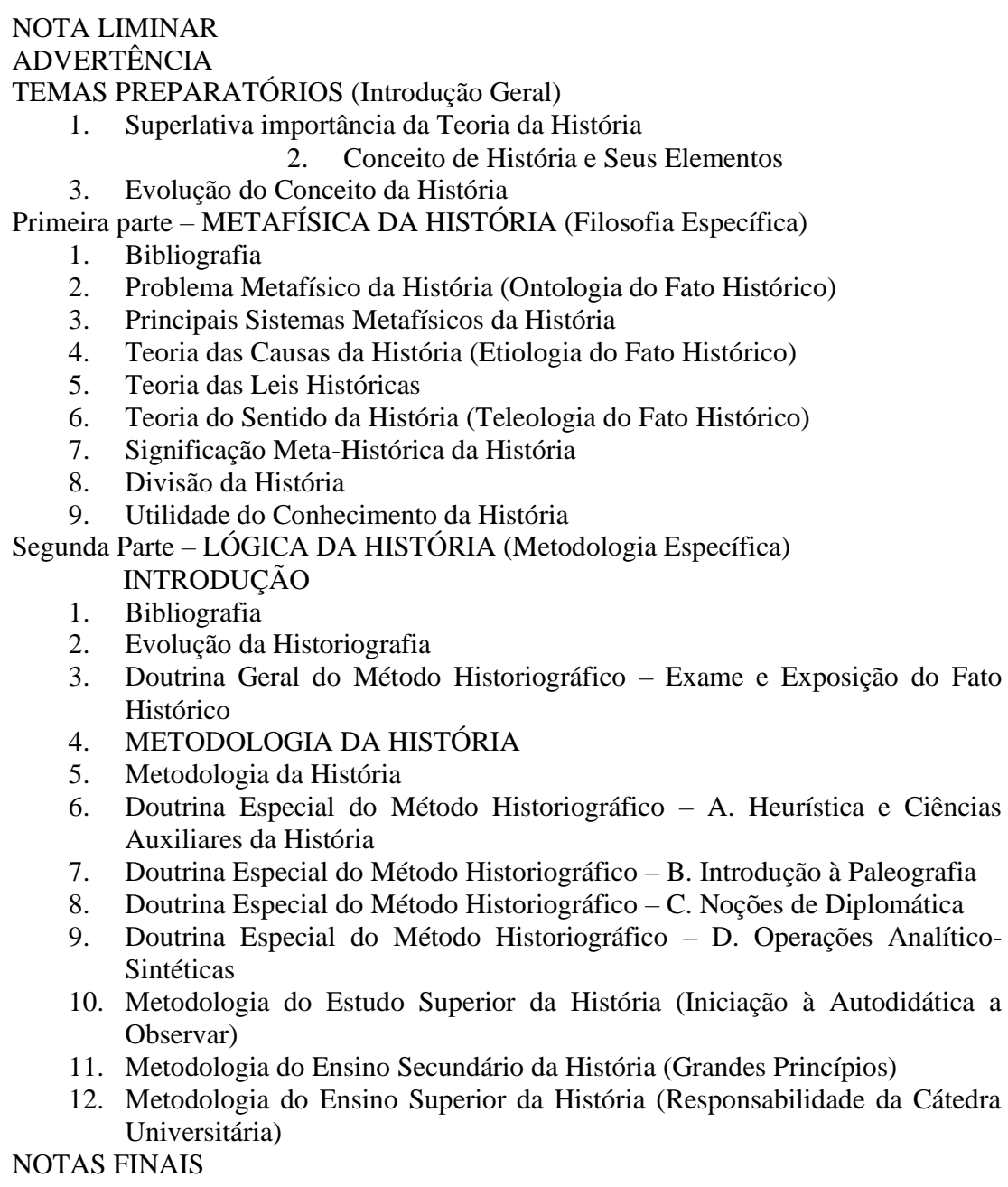

2. Evolução da Historiografia

3. Doutrina Geral do Método Historiográfico - Exame e Exposição do Fato Histórico

4. METODOLOGIA DA HISTÓRIA

5. Metodologia da História

6. Doutrina Especial do Método Historiográfico - A. Heurística e Ciências Auxiliares da História

7. Doutrina Especial do Método Historiográfico - B. Introdução à Paleografia

8. Doutrina Especial do Método Historiográfico - C. Noções de Diplomática

9. Doutrina Especial do Método Historiográfico - D. Operações AnalíticoSintéticas

10. Metodologia do Estudo Superior da História (Iniciação à Autodidática a Observar)

11. Metodologia do Ensino Secundário da História (Grandes Princípios)

12. Metodologia do Ensino Superior da História (Responsabilidade da Cátedra Universitária)

NOTAS FINAIS

Figura 1.

Plano da obra Teoria da História (1966) de Roberto Piragibe da Fonseca Fonte: FONSECA $(1966,11)$.

No que diz respeito à matéria, como apresentada pela figura 1, a Teoria de Fonseca privilegiou dois objetos-disciplina: "Metafísica da História" e "Lógica da História". Assemelhava-se ao impresso de Introducão aos estudos históricos (1954/1958), de José Van den Besselaar (1906-2001) e apresentava orientação diversa à Iniciação aos Estudos Históricos (1961), de Jean Glénisson (1921-2010). 
Besselaar e Glénisson foram professores de cursos propedêuticos da Universidade de São Paulo (USP) entre 1957 e 1959 (Gary 2006; Roiz 2007, $92-$ 93). Besselaar, especialista em estudos clássicos e doutor em Filologia Clássica pela Universidade holandesa de Nimega (Freire 1978, 335), por um lado, compreendia um curso de Introdução à História como ferramenta para a iniciação dos alunos "nos métodos, nos instrumentos e nos pressupostos filosóficos da disciplina tão complexa, que é a História". Mas, estabelecia uma progressão. No primeiro ano, o aluno estudava as categorias básicas (História, Período etc.), algumas questões metafísicas (certeza, processo) e, principalmente, as operações da "investigação histórica" e da "síntese histórica". Para os alunos do segundo e do terceiro ano, Besselaar prescrevia o estudo da história da historiografia (da Grécia Clássica à Ásia no século XIX) e as principais tendências em termos de Filosofia Especulativa da História (Besselaar 1954/1958).

Glénisson, por outro lado, arquivista-paleógrafo formado na École Nationale des Chartes (1946), lamentava que "alguns dentre eles - e os mais brilhantes [alunos se admirassem], por vezes, de não lhes ser ministrado um curso de filosofia da história: uma filosofia da história tomada no sentido hegeliano de especulação sobre o porvir da humanidade vista no seu conjunto". Preferia as orientações de Marc Bloch (1866-1944): formar para o exercício do "ofício do historiador", o que significava estruturar um curso sobre o exame da historicidade da disciplina, relativa ao tempo do "triunfo do método crítico" (1850-1900), e sobre o "método" e as "técnicas" que poderiam converter o "amador de história" em "historiador consciente" (Glénisson 1991, 6).

$\mathrm{Na}$ contramão desse espírito antifilosófico - mais propriamente atribuível a Langlois e Seignobos que a Marc Bloch, como interessadamente reivindicou Glénisson -, Fonseca abre o seu livro (que espelha as suas aulas) com preleções-capítulos de Metafísica, seguidas por preleções-capítulo de Lógica. Na primeira parte (Metafísica), ocupa-se da natureza, origem e finalidade da História. Na segunda (Lógica), fornece os "métodos que permitem obter a verdade histórica", ensinar História em nível médio, estudar e ensinar a História em nível superior (Fonseca 1967, 20, 23). Sua Teoria da História, como vemos, trata da existência da coisa e da possibilidade de conhecimento da coisa em campos separados. Essa opção por ontologia e epistemologia vai determinar a noção de objetividade do conhecimento histórico difundida entre os alunos.

De onde retira tal disposição de matéria, em geral, Fonseca não informa. O texto didático, entrecortado por esquemas, listas e narrativas sumárias foi para ele, provavelmente, um obstáculo à referenciação, questão a questão e tese a tese, aqui descrita na figura 2. Mas o cruzamento das suas proposições com as sentenças apresentadas em alguns dos livros indicados para a leitura (aqui examinados de modo não exegético) nos possibilitam conhecer algumas ideias recuperadas de tempos longínquos, ideias apropriadas do seu tempo e o resultado compósito da sua noção de "teoria da História". 


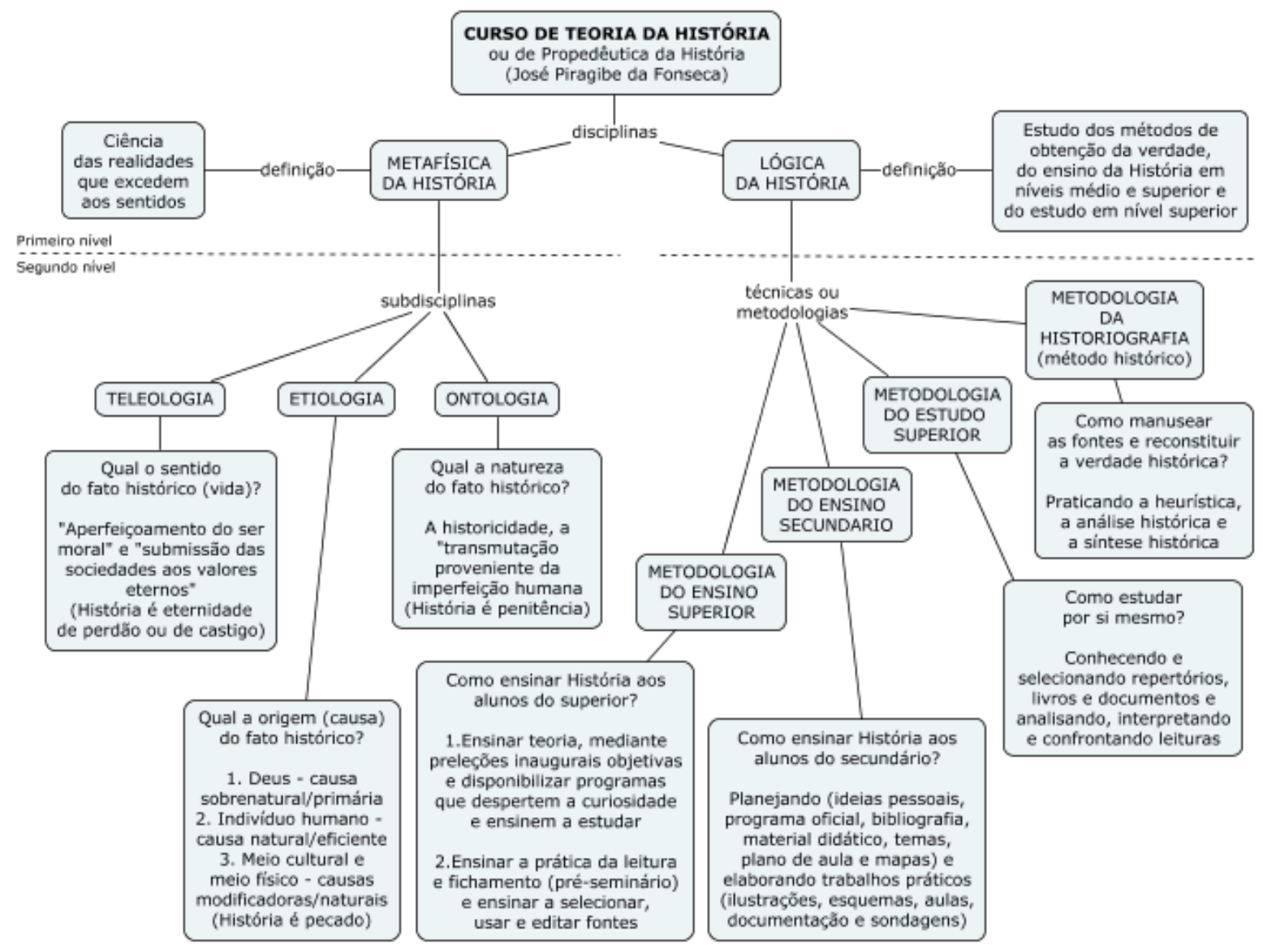

Figura 2.

Mapa conceitual do Curso de Teoria da História de Roberto Piragibe da Fonseca (1966). Fonte: Produzido pelo autor, a partir da leitura de Fonseca (1966).

As escolhas pela Metafísica e pela Lógica são indicadores da sua militância em favor da História-ciência e da Ciência a serviço do catolicismo. Manuais correntes, dominantemente, punham ênfase em questões de método de pesquisa e escrita da história ou em questões sobre a natureza e a direção do processo histórico. Comparado aos manuais publicados na França (e citados por Fonseca), por exemplo, o Manual da Teoria da História assemelhava-se ao impresso "filosófico-crítico" de H.-I. Marrou (1904-1977) - De la connaissance bistorique (1954) - e se distanciava, em parte, do "metodológico" Introduction à l'histoire (1941), de Louis Halphen (1880-1950). Na França e em outros países europeus e americanos, manuais de método (com alguma discussão sobre metafísica) eram majoritários. Nos cursos de formação de bacharéis em Teologia e em Filosofia, manuais de Filosofia Especulativa da História (com alguma discussão sobre metodologia da História) ganhavam proeminência. No curso preparado para os alunos da PUC/RJ, Fonseca tomou a decisão de conjugar metafísica e lógica e de situar, curricularmente, a lógica em momento posterior à metafísica.

Embora grande parte de suas referências bibliográficas fizesse coro contra o materialismo (de Comte, Spencer, Marx e Engels) e denunciasse os resultados do esgotamento das filosofias racionalistas da História (a Grande Guerra, a Revolução Russa, o Comunismo, Hitler e o uso efetivo da bomba atômica), significar Teoria da História como conjunção de Metafísica e Lógica não era uma decisão pacífica. 
A disposição adotada por Fonseca difere dos livros que ele próprio indica em ordem, objeto e densidade da matéria. Dos autores citados no Manual, parte ocupava postos em universidades e parte era formada por outsiders destacados nos estudos históricos e filosóficos sobre o cristianismo e o catolicismo. Herbert Butterfield (1900-1979), por exemplo, inglês, católico e historiador, que escrevera Cristianismo e História (Christianity and History - 1950), criticava a formação centrada na metodologia da História e enfatizava a importância das competências do "poeta, do profeta, do teólogo e do filósofo". A combinação "da história com uma religião ou com algo equivalente a uma religião", ao contrário da aridez da crítica histórica, ele afirmava, preencheria o processo histórico com significados (Butterfield 1950, 23-24).

Franz Sawicki (1877-1952), doutor em Teologia (Freiburg), autor de vários títulos sobre cristianismo e catolicismo - entre os quais o Filosofia da História (Geschichtsphilosophie - 1920), outro indicado por Fonseca, - não empregava "Teoria da História" para articular Metafísica e Lógica em um único domínio. Preferiu a expressão "Filosofia da História" que, segundo o próprio autor, nomeava um campo, à época, sobrepujado em quantidade pelos títulos de "Lógica da História", na passagem do século XIX para o XX (Sawicki 1920, 3). Especialista em teoria do conhecimento, Sawicki não chegou a reservar um terço do seu manual à parte da Lógica, específica para a pesquisa histórica, no segmento relativo ao conhecimento histórico.

Fonseca se distancia desses dois trabalhos e autores ao reservar o mesmo espaço em seu impresso para a Metafísica e para a Lógica e ressignificar, em parte, esses dois domínios ou disciplinas da Filosofia. Sawicki, como Fonseca, era um entusiasta da "filosofia cristã da História", mas a sua teleologia não pareceria suficiente ao brasileiro que empregou $A$ cidade de Deus (413/426) para reforçar o valor das teses de Santo Agostinho (354-430) na formulação da "concepção católica da História" em sua "fase teocrático-dualista inicial" (Fonseca 1966, 44), como explicitado a seguir, pelas próprias palavras do Bispo de Hipona.

\footnotetext{
muitos dos que agora desacreditam o Cristianismo e imputam a Cristo as desgraças que a cidade teve que suportar [...] [d]everiam antes, se o avaliassem judiciosamente, atribuir os sofrimentos e durezas que os inimigos lhes infligiram à divina Providência que costuma, com guerras, purificar e castigar os costumes corrompidos dos homens. É a divina Providência que põe à prova a vida justa e louvável dos mortais com tais aflições, para, uma vez provada, ou a transferir para uma vida melhor ou a reter nesta Terra para outros fins. (Agostinho 1996, 101-102).
}

Butterfield, conhecedor das virtudes e, principalmente, das limitações dos rudimentos da erudição histórica, teria sido bastante contrariado com a atitude de Fonseca em adotar doutrinariamente as regras (de Lógica da História) de heurística, crítica e interpretação disseminadas por antimetafísicos, como Langlois e Seignobos, mas não apenas. Fonseca sugere a leitura de propedeutas antimetafísicos que pensaram a formação de professores a partir da ênfase no aprendizado de regras de crítica e interpretação, como as produzidas por Marc Bloch (1886-1944), da heurística, crítica de fontes e inferência a partir das fontes criticadas, produzidas por Kristian Erslev (1852-1930), além das orientações para o ensino secundário, contidas na didática geral de Alfredo Sánchez (18661848) e na metodologia do ensino de história de Jonathas Serrano (1885-1944). 
Quando descemos ao segundo nível de distribuição de matéria - a Metafísica como Ontologia, Etiologia e Teleologia e a Lógica como metodologia da pesquisa, do ensino e do estudo (figura 2) -, percebemos, de modo mais claro que as apropriações das teses dos indicados para a leitura vão dando a ver um novo produto chamado "Teoria da História" (se não à brasileira, ao menos puquiana e carioca).

$\mathrm{Na}$ descrição da Teleologia, Fonseca se identifica com o Ensaio de uma filosofia do destino humano (Essai d'une philosophie de la destinée humaine -1921/23) de Nicolas Berdiaeff. Mas, pode ter pensado que o russo - crítico da Filosofia de Marx, dos positivistas e dos evolucionistas e empenhado na construção de uma "filosofia religiosa da história" - se equivocava ao empregar "objeto" em sentido escolástico ou, quem sabe, por desconsiderar a possibilidade de um conhecimento objetivo dos fatos históricos (coisas existentes e exteriores ao sujeito - objetivos sob o ponto de vista ontológico e epistemológico). Berdiaeff afirmou que o "objeto" do "conhecimento histórico não [era] o empírico, mas a existência além túmulo" (Berdiaeff 1923, 10-11).

Para Fonseca, o objeto do conhecimento histórico eram as "ações racionais do homem, por ele praticadas como ser social, isto é, ocorridas no tempo e no espaço". Foi essa posição, inclusive debitária do distante Agostinho (livre-arbítrio) e do próximo Bernheim (ser social), que forneceu o núcleo duro da sua definição de História: "é a ciência que investiga, conhece e expõe as ações racionais do homem, por ele praticadas como ser social, isto é, ocorridas necessariamente no tempo e no espaço, interconexas, vinculadas cada uma de per si à motivação respectiva, e voltadas todas à causa da Civilização" (Fonseca 1966, 27).

Na descrição dessa Ontologia, ocorreu o contrário. Quando se servia da tese da historicidade do fato histórico (Fonseca 1966, 41, 49), anunciada pelo jesuíta e professor de Filosofia em Walkemburg, August Brunner (1894-1985), em Questões básicas de Filosofia (Die Grundragen der Phisolophie: ein systematischer Aufban - 1933), Fonseca deve ter reprovado Brunner (especialista em teoria do conhecimento) por não avançar além da ideia de que as ações dos indivíduos resultavam em escolhas com base em experiência pretérita, que desencadeavam novas escolhas, ou seja, que eram mutáveis (Brunner 1963, 171-172, 179-180). Em sua Teoria da História, Fonseca explicou a historicidade do fato a partir da Teleologia pensada por Santo Agostinho: as coisas mudam (o caráter do fato é a sua inerente historicidade) por causa do "drama da imperfeição humana" (Fonseca 1966, 49).

Para a etiologia e a ontologia do "fato histórico", as posições de Sawicki foram também desenvolvidas e exemplificadas com asserções sobre a valência providência e do livre-arbítrio, como também sobre o poder modificador do meio físico-cultural. Nesse sentido, a tipologia das causas - 1. "primária" (Deus), 2. "eficiente" (Homem) e 3. "modificadoras" (meio físico e psiquê) - formuladas por Fonseca, resultou da crítica à "prolixa" classificação do produtor de manuais de metodologia histórica (e também ideólogo cristão) Zacarías García Villada (1879-1936) (Fonseca 1966, 50).

Esses foram alguns dos diálogos entretidos para a construção da sua Metafísica. Da parte Lógica, percebemos uma ausência significativa: a discussão sobre a natureza do conhecimento histórico e o seu lugar no concerto das ciências. Em brevíssimo período, ele classifica a História como ciência do tipo nomotético, sob os argumentos de Gabriel Monod (1844-1912). Na maioria dos manuais propedêuticos dominantemente marcados pela metodologia (ou pela Lógica de Fonseca), essa classificação ocupa largo espaço na mancha. 
Observando outra vez a figura 2, contudo, percebemos que essa questão (lógica em Sawicki) foi deslocada para as subdisciplinas metafísicas: o objeto da ciência histórica é o fato histórico (ontologia) multicausado (etiologia) e previsível, embora não obediente a leis ao modo das ciências naturais (teleologia). O caráter científico da História é, portanto (e primeiramente), um problema de fundo ontológico (a realidade existe fora do sujeito conhecedor), expresso por negação à gnosiologia proposta por Kant (que, como afirmou Daston, não estava interessado na metafísica do seu tempo). A cientificidade é justificada, em seguida, com o anúncio do aparato metodológico empregado na pesquisa e na exposição dos fatos.

Nesse segundo nível hierárquico da sua parte Lógica, percebemos uma inovação. Observem que Fonseca salta imediatamente da Lógica para as "metodologias". Na sua Teoria da História, não há "o" método histórico como determinante das "metodologias": há métodos históricos destinados a ensinar no secundário, no superior, a estudar no superior e a pesquisar e escrever história. Esses métodos definem ao menos três (senão quatro) domínios ou protocampos de investigação: a "Metodologia do Ensino Superior", a "Didática da História" e a "Metodologia da Pesquisa".

Naquele ano de lançamento (1966), a Metodologia do ensino Superior de História não era convencionalmente assumida pelos catedráticos como matéria formativa. A profissionalização (pedagógica) do ensino, não apenas no Brasil, entre o último terço do século XIX e o primeiro do século XX, em geral, era fenômeno restrito aos ensinos primário e secundário. Assim, o apelo de Fonseca, mesmo em termos transnacionais, era (e ainda é, no caso brasileiro) algo novo: "Cuide-se da formação do professor universitário, para que, a bem da cultura nacional, o candidato à docência superior não mais se veja compelido a esperdiçar tempo, tão lamentavelmente, com a própria formação, autoformação, aliás, sempre e inevitavelmente defeituosa" (Fonseca 1966, 145). A solução apresentada era a adoção do método de ensino exegético, em termos teóricos, e a instituição dos pré-seminários e seminários (figura 2), ao modo do jesuíta Leopold Fonck (1865-1930) que escrevera Trabalhos cientificos. Contribuição para uma metodologia dos estudos acadêmicos (Wissenschaftliches Arbeiten - Beiträg zur Methodik des akademischen Studiums - 1908).

O segundo protocampo era "Metodologia do Ensino secundário da História", já radicada nas faculdades de Filosofia ou Educação e nas escolas normais brasileiras. A proposta de Fonseca não destoava das iniciativas designadas como Didática Especial de História e Metodologia do Ensino de História. A Metodologia era o fórum das discussões sobre a natureza psicológica do aluno, os valores e os conhecimentos requeridos ao professor e, consequentemente, o domínio dos conteúdos substantivos e das técnicas de "transmissão ao adolescente" (FONSECA 1966, 135). Como vemos pelo temário, Fonseca não explora a parte prática, reservada aos pedagogos. Também não incorpora a inovação de citados na bibliografia, como o clássico Teaching of history in elementary and secondary schools (1942), de Henry Johnson (1867-1953), que já prescrevia a transposição das operações metodológicas de pesquisa para os alunos do secundário.

O terceiro e o quarto protocampos são o "estudo" e a "pesquisa e exposição" históricos. O "Estudo" é uma zona cinzenta para nós. Pode representar uma tradução dos "studies" comuns em manuais estadunidenses e ingleses, às vezes interpretados como "investigação" histórica ou como práticas de acompanhamento de cursos em nível superior (práticas de estudo). Quanto à sua "Metodologia do Estudo superior da História", ela reúne orientações 
destinadas ao trabalho "autodidático" para quem quer, por exemplo, escrever uma tese de pós-graduação. Suas prescrições dispõem, basicamente, sobre as regras e recursos para localizar e selecionar fontes e bibliografia e regras para criticar, interpretar e confrontar "leituras" (Fonseca 1966, 133). Essas orientações pressupõem o conhecimento da "Doutrina Especial do Método Historiográfico" ou, simplesmente, "historiografia". Ela dá conta da classificação e crítica das fontes (heurística), da "autenticidade/genuinidade", "veracidade/clareza" (análise) e da "hermenêutica, construção, generalização e exposição das fontes" (síntese) (Fonseca 1966, 123, 126).

\section{OBJETIVIdAdE NA CiÊnCIA dA HistóRIA}

A "objetividade" ou o caráter "objetivo" do "conhecimento histórico" na Teoria da História de Fonseca é um problema de Lógica. Mas, vimos que sua Lógica histórica não se resume à prescrição do método triádico da pesquisa histórica. Ela engloba questões de Teoria geral do conhecimento e de métodos para o ensino e o estudo da História. Assim, de início, concordemos que não há apenas uma diretriz para a garantia de um conhecimento objetivo do passado que poria a História no mesmo patamar controlado das Ciências Naturais. Podemos afirmar que ele prescreve níveis de objetividade sob o ponto de vista das metodologias e uma hierarquia entre os critérios de validação, no interior de algumas tarefas relativas a essas mesmas metodologias.

$\mathrm{Na}$ exposição da metodologia do ensino secundário, ser objetivo significa escrever (um livro didático) com "imparcialidade e ânimo conciliador", isto é, manter-se a "meio-termo" entre o protagonismo dos heróis de Thomas Carlyle (1795-1881) e o protagonismo das classes sociais de Hippolyte Adolphe Taine (1828-1893). Isso porque a função do professor, nesse nível de ensino, é expor e explicar os fatos (Fonseca 1966, 139-140), mas nunca os interpretar. Fonseca concebe o aluno do ensino secundário como um receptor de conhecimento histórico - que se deixa "modelar docilmente pelo mais experiente" - e o professor, consequentemente, como um transmissor da pesquisa produzida nas cátedras universitárias - que "manipula jovens entre onze e dezoito anos" (Fonseca 1966, 21).

$\mathrm{Na}$ metodologia do ensino superior, onde a função docente é deslocada para a interpretação ("exegese" ou "hermenêutica"), a "objetividade da exposição" pode ser garantida, inicialmente, com a "apreciação do respectivo clima intelectual e espiritual" do período histórico estudado, elementos que determinam os fatos de "ordem política, econômica e social" (Fonseca 1966, 149. Grifos do autor). Em outras palavras, a "possibilidade" e a "verossimilitude" dos fatos da política são mensuráveis a partir do reconhecimento dos ideais superiores e dominantes em cada tempo.

Esse critério parece condenar o ensino de História Contemporânea, já que o espírito do tempo não se mostraria claramente ao historiador que nele estivesse imerso. Era uma preocupação partilhada pelos colegas professores que lhe questionam sobre a viabilidade do ensino de História dos "tempos mais recentes", ou seja, dos acontecimentos de até 50 anos anteriores ao momento da preleção. Fonseca, porém, não vê problemas nesse sentido. Responde que a objetividade da preleção desses tempos quase coetâneos à vida do professor depende de uma habilidade "pessoal e técnica": o "discernimento". Esse atributo racional/moral está expresso no "método de transmissão" que prescreve a sobriedade das falas e das fontes, como também o respeito ao contraditório: 


\begin{abstract}
a) observação fria dos eventos: o professor neófito, principalmente, deve expô-los com objetividade máxima, quase com secura, evitada quanto possível a adjetivação, assim como também, quanto possível, dispensado o comentário pessoal;

b) uso de documentação sóbria em apreciações e de procedência rigorosamente insuspeita, máxime quando se tratar de assunto capaz de gravemente suscitar e ferir melindres;

c) neste caso, - providência complementar -, recorrer sistematicamente a opiniões concorrentes (Fonseca 1966, 161).
\end{abstract}

No que diz respeito ao método de "exame e exposição do fato histórico", a "conclusão pela objetividade do conhecimento histórico" é mediada pelo adequado cumprimento das três principais tarefas do "método histórico": constatação dos fatos, explicação dos fatos e julgamento dos fatos históricos.

$\mathrm{Na}$ "constatação" e na explicação dos "fatos históricos" (primeira e segunda operações), as conhecidas e circulantes tarefas de crítica externa e crítica interna são abonadas por Fonseca. Ele incorpora a ideia de que as fontes passíveis de uso pelo historiador devem ser testadas e certificadas no que diz respeito ao pleno conhecimento dos seus autores e da sua procedência e ao grau de conservação da sua integridade original. Até aqui, Fonseca segue princípios dominantes. $\mathrm{Na}$ crítica interna, contudo, julgadora da "possibilidade e verossimilitude das fontes", Fonseca põe a sua marca (ou a marca dos teóricos católicos): a objetividade do conhecimento histórico está condicionada à preservação de uma hierarquia de valores relativos a verdades reveladas e verdades demonstradas. Daí considerar impossível e inverossímil um fato que

[...] encerra contradição interna. V.g., é metafisicamente impossível que o ato sabidamente originário de necessidade inelutável, seja ato proveniente de livre autodecisão. Tem valor absoluto a impossibilidade metafísica.

[...] contradiz hábitos arraigados de natureza moral. $V . g$., é moralmente impossível que um pai odeie o próprio filho. Tem valor relativo à impossibilidade moral.

[...] contradiz as leis da natureza. Tem valor mais relativo, ainda, dado ser temerário falar inconsideradamente de impossibilidade física, primeiro, porque o homem só muito imperfeitamente conhece as forças da natureza e, segundo, porque - realidade apodítica -, o governo da Providência divina pode intervir diretamente na ordem do Cosmos, derrogando, momentânea e excepcionalmente, as leis físicas, mediante o milagre (Fonseca 1966, 95-96. Grifos do autor).

$\mathrm{Na}$ terceira operação do método da pesquisa e da exposição, a de julgamento, o apreço ao trabalho objetivo também deve ser observado pelo professor: "assinalar com objetividade ascensões e decadências, progressos e regressos e sempre que presidido o juízo por norma que corresponda ao ideal de civilização da maioria" (Fonseca 1966, 97). Trata-se, como veremos a seguir, de critério defendido nos manuais de Bernheim e de Wilhelm Bauer (1877-1953), de onde é provável que Fonseca o tenha extraído (Bernheim 1903, 716-717; Bauer 1921, 87). Podemos afirmar que esse axioma corresponde à parte mais conhecida dos argumentos que combatem o ceticismo acerca do conhecimento histórico e a defesa da História como ciência (e não literatura de ficção). A defesa da possibilidade de um conhecimento objetivo mediante investigação histórica descende, efetivamente, do reconhecimento das limitações do historiador e das suas ferramentas de trabalho, como também de argumentos lógicos produzidos contra o Kant da Crítica da razão pura (a impossibilidade de conhecimento da coisa em si). Vejamos, primeiro, essa questão afeita à Teoria geral do conhecimento. 
O argumento de que é possível conhecer objetivamente o que está fora do sujeito conhecedor possui extenso histórico de defesas, desde a Filosofia do inconsciente (Philosopbie des Unbewussten - 1869), de Eduard von Hartmann (18421906) até a Carta Encíclica Pascendi Dominici Gregis - 1907), de Pio X (1835-1914). Já afirmamos que Fonseca nem sempre revela a proveniência dos seus empréstimos, mas não é difícil perceber que ele retira o seu argumento do livro de Sawicki que, contrariando Kant, afirma existir um mundo interior e subjetivo (das ideias e imagens) e um mundo exterior e objetivo (das coisas sensíveis). Se "os fatos históricos pertencem ao mundo sensorial (se são materiais) e desaparecem com ele", é possível não apenas um conhecimento mediado por ação interior (como afirmava Kant), mas também uma objetividade exterior. Sawicki reconhece que tal objetividade não significa "réplica exata" do exterior, posto que os representadores da realidade deixam vazar as suas subjetividades. Mas o extremo contrário também não ocorreria, porque nenhum historiador produziria um mundo particular de signos sem correr risco de tornar-se incompreensível aos pares (Sawicki 1920, 283).

O segundo argumento, relativo à limitação do historiador e das suas fontes, Fonseca retira (também provavelmente) do livro de Sawicki que, por sua vez, o extrai do manual de Bernheim. Fonseca também cita Bernheim, mas modifica parte do seu argumento sobre as possibilidades de o historiador produzir um conhecimento objetivo sobre o passado. Bernheim reconhece que o trabalho do historiador depende da disponibilidade de fontes, da natureza, da completude e veracidade dos testemunhos. Para garantir a satisfação mínima dessas exigências, Bernheim apresenta as regras de heurística, crítica e interpretação (também adotadas por Fonseca). Mas não vê saída indiscutível no que se refere à intromissão dos valores do historiador no trabalho de interpretação das fontes, de conexão dos fatos e produção do relato. Assim, propõe uma hierarquização. O historiador que balizasse o seu trabalho metódico pelos mais altos valores estaria menos propenso a corromper a representação do acontecido.

Implicitamente, Fonseca concorda com essas proposições, mas não opera com o mesmo fundamento dos universais antropológicos de Bernheim. Para o brasileiro, há unidade humana, origem, motor e sentido, mas esses elementos são melhor descritos por Santo Agostinho e não por Rudolf Hermann Lotze (1817-1881), o filósofo empregada por Bernheim. Assim, o segundo modo de tornar o conhecimento histórico objetivo, segundo Fonseca, seria adotar a escala de valores cristãos e católicos para o julgamento dos fatos.

Assim, a objetividade histórica promovida pelo historiador, como afirmamos, estaria na terceira operação do método de investigação, ou seja, no ato de julgar os fatos, substituindo "o quanto possível, o ideal cultural próprio [o ideal grupal/individual do historiador] pelo ideal cultural esposado pelo consenso geral" (Fonseca 1966, 97). Em outros termos, a objetividade, nesse nível de aplicação, dependeria de o historiador reconhecer que o "consenso geral" era fornecido pela metafísica cristã e católica. Entre os valores que balizariam tais julgamentos estariam, provavelmente, o "idealismo" e o "altruísmo" (antíteses do materialismo e do egoísmo), segundo Fonseca, os "móveis das ações humanas" (Fonseca 1966, 53). 


\section{CONSIDERAÇÕES FINAIS}

Até aqui, tentamos convencê-los de que a Teoria da História de Piragibe da Fonseca é um compósito de estruturas de manuais e de listas de teses defendidas por autores, em geral, cristãos, antimaterialistas que circulavam em instituições educacionais universitárias e não universitárias da Alemanha, Áustria, Brasil, Dinamarca, Espanha, EUA, França, Hungria e Inglaterra. Estruturada nas disciplinas-campo da Metafísica e da Lógica, a Teoria da História de Fonseca é uma espécie de cluster, onde cada unidade possui relativa independência. Essa estrutura é clara na Lógica, na qual as metodologias de ensino do superior, ensino do segundo grau e estudo de História no superior não reproduzem literalmente "o" método da pesquisa e da exposição históricas.

Certamente, os critérios de validação da "verdade" histórica são dados pelo "método", ou seja, os critérios de validação estão anunciados nas tarefas de "constatação dos fatos históricos" via crítica externa (autenticidade/integridade/autoridade da fonte) e crítica interna (autoridade do narrador, possibilidade e verossimilitude das fontes). Os critérios de validação das verdades prescrevem, por exemplo, a ausência de contradição entre ação humana e necessidade, entre ação humana e lei moral e entre fenômeno natural e leis física. Ocorre que, na Lógica de Fonseca, tais critérios estão embebidos de princípios metafísicos. É impossível, por exemplo, aceitar que a felicidade dos trabalhadores no planeta pode ser instaurada a partir do fim da luta de classes, quando se sabe que a vida na Terra é intrinsecamente sofrimento decorrente do pecado. Tal proposição não é válida porque contradita a necessidade providencial. É impossível negar a travessia dos hebreus pelo leito seco do Mar Vermelho, quando se sabe que o conhecimento humano sobre as leis físicas é imperfeito e, ainda, que a Providência pode alterar "a ordem do Cosmos". Tal proposição pode ser válida porque conserva coerência acerca do valor relativo que possuem as leis da natureza. Além da interferência desses princípios metafísicos, a conclusão pela "objetividade do conhecimento histórico" é conduzida por diferentes critérios de validação (metafísicos e físicos), geridos sob diferentes pesos (valor absoluto - é impossível ferir leis metafísicas; valor relativo - é possível ferir leis morais e físicas) e contrapesos (aceitação do milagre limitada à validação das suas fontes em termos de crítica externa).

Essa concepção de objetividade do conhecimento histórico tem implicações para as nossas tentativas de classificação da sua teoria e para a construção de eventuais histórias da Historiografia ou histórias da Teoria da História no Brasil. Em primeiro lugar, e retomando o debate exposto na introdução deste artigo, podemos afirmar que o emprego de uma periodização para a história da objetividade histórica que prescrevesse a transição de um tempo de imparcialidade para um tempo de objetividade, como sugere Daston e Galison, seria contraditado, por exemplo, pela Teoria da História de Fonseca para quem a parcialidade do historiador e do professor de História do ensino superior era também constituinte da objetividade do conhecimento histórico, assemelhando, desse modo, a experiência brasileira à experiência de vários exemplares da historiográfica alemã do século XIX (Assis, 2015; Freitas, 2019).

Em segundo lugar, e considerando a presença de valores religiosos, pesos e contrapesos, alguns dos quais determinados por metafísicos, a presença do "método histórico" (em suas clássicas operações de heurística, análise e síntese) não seria causa suficiente para tipificar escritos como os de Fonseca (dentro do IHGB e das Faculdades de Filosofia) como prescritores de objetividade mecânica ou (o que é mais comum) de certo ideal metodológico positivista, 
difundido, por exemplo, por A. Comte, H. Buckle, E. Durkheim e F. Simiand. Em outros termos, a existência de um método científico não garantiria por si só o caráter científico da História.

Por fim, e em contrapartida ao anunciado acima, não podemos afirmar que Teorias da História, como as de Fonseca, estariam justificando a cientificidade da História somente a partir de domínios da Filosofia, ou seja, que o domínio da Teoria da História se reduziria ao domínio da Metafísica ou da Lógica. Evidentemente, a Teoria de Fonseca não se configura um exemplar de "Epistemologia Histórica" ou de "Historiografia epistemológica", no sentido indicado por Tiago Almeida (2018, 25-26). Fonseca não reserva a maior parte de seu livro para a historicização de princípios e práticas interna corporis. Entretanto, não podemos negar o esforço do professor carioca em reunir um conjunto de teses e de práticas de assentimento geral entre pares cristãos e não cristãos, no sentido de defender determinada autonomia para a legitimar (socialmente) aquilo que produzem com o nome de História científica.

\section{REFERÊNCIAS}

ALMEIDA, Tiago Santos. Introdução - Combates pela história das ciências. In: Canguilhem e a gênese do possível: estudo sobre a historicização das ciências. São Paulo: LiberArs, 2018. 18-32.

ASSIS, Arthur Alfaix. Objectivity and the first law of History writing. Journal of the Philosophy of History. Leiden, 1-23, 2016. Disponível em: https://www.academia.edu/31173845/Objectivity_and_the_First_Law_of_History _Writing_2019. Capturado em: 12 mai. 2018.

BARRETO, Dalmo. Roberto Piragibe da Fonseca. Revista do Instituto Histórico e Geográfico Brasileiro. Rio de janeiro, v.147, n.352, 951-954, jul./set. 1986.

BAUER, Wilhelm. Einfürung in das Studium der Geschichte. Tübingen: J.C.B Mohr, 1921.

BEARD, Charles Austin. Aquele sonho nobre [1935]. In: MALERBA, Jurandir (org.). Lições de História: da História científica à crítica da razão metódica no limiar do século XX. Porto Alegre: EDIPUCRS/FGV, 2013. 338-353.

BERNHEIM, Ernst. Lehrbuch der Historischen Methode und der Geschichtsphilosophie. Leipzig: Duncker \& Humblot, 1903.

BESCIANI, Maria Stella Martins. O charme da ciência e a sedução da objetividade: Oliveira Vianna entre intérpretes do Brasil. São Paulo: Unesp, 2005.

BESSELAAR, Jean Van Den. Introdução aos estudos históricos. São Paulo: [USP], 1954/1958.

BESSELAAR, José van Den. Introdução aos estudos históricos. 3ed. São Paulo: Editora Pedagógica Universitária, 1973. 
CAMARGO JÚNIOR, M. C. V. Questões sobre a profissionalização da História: a disciplina Introdução aos Estudos Históricos no I Simpósio de Professores de História do Ensino Superior (1961). Fato \& Versões, [sdt], v.8, 70-89, 2016.

CAMPOS, Milton. Parecer n.443, de 1959. Diário do Congresso Nacional. Brasília, 1871, 06 ago. 1959. Disponível em:

https: / / legis.senado.leg.br/diarios /BuscaDiario?tipDiario $=1 \&$ datDiario $=26 / 08 / 19$ $59 \&$ paginaDireta $=1871$ \&indSuplemento $=$ Nao\&codSuplemento $=\& d e s$ VolumeSupl emento $=\& d e s$ TomoSuplemento $=$ Capturado em: 05, fev. 2010.

CELESTINO, Basílio. Requerimento n.324, de 1959. Diário do Congresso Nacional. Brasília, 2108,01 set. 1959. Disponível em: https://legis.senado.leg.br/diarios/BuscaDiario?tipDiario=1\&datDiario=19/09/19 59\&paginaDireta $=2108 \&$ indSuplemento $=$ Nao\&codSuplemento $=\&$ des VolumeSupl emento $=\& d e s$ TomoSuplemento $=>$ Capturado em: 05, fev. 2010.

CODATO, Adriano Nervo; GUADALINI JÚNIOR, Walter. Os autores e suas ideias: um estudo sobre a elite intelectual e o discurso político do Estado Novo. Estudos Históricos, Rio de Janeiro, n.32, 154-164, 2003.

COLLINGOOD, Robin George. Ideia de la historia (Edición revisada que incluye lass conferencias de 1926-1928). México: Fondo de Cultura Económica, 2004.

COTTINGHAM, John. A Descartes Dictionary. Oxford: Blackwell, 1993.

DASTON, Lorraine; GALISON, Peter. Objectivity. New York: Zone Books, 2007.

DESCARTES, René. Discurso do Método (1637). São Paulo: Nova Cultural, 1993 a.

DESCARTES, René. Meditações (1641). São Paulo: Nova Cultural, 1993 b.

ESPONSEL, José Pedro Pinto. $1^{\circ}$ Encontro Brasileiro sobre Introdução ao Estudo da História - Anais. Niterói: Universidade Federal Fluminense; Instituto de Ciências Humanas e Filosofia, 1970.

FERREIRA, Marieta de Moraes. A história da história no Rio de Janeiro: da UDF à UFRJ. In: A história como ofício: a constituição de um campo disciplinar. Rio de Janeiro: FAPERJ; FGV, 2013. 17-82.

FICO, Carlos; POLITO, Ronald. A história no Brasil (1980-1989): elementos para uma avaliação historiográfica. Ouro Preto: UFOP, 1992.

Folha da Manhã. Cadeira de Metodologia da História nas faculdades de Filosofia e Letras. São Paulo, 6 ago. 1955.

FOLHA DE SÃO PAULO. Questões de metodologia da história / A história e a reforma geral do ensino. São Paulo, 23 abr 1974. Educação, 17.

FOLHA DE SÃO PAULO. Questões de metodologia da história na SBPC. São Paulo, 10 jul. 1973, Educação, 11.

FONCK, Leopold S. J. Wissenschaftliches Arbeiten - Beiträge zur Methodik das akademischen Studiums. Insbruck: Felizian Rauch, 1908.

FONSECA, Roberto Piragibe da. Metodologia da História - elaboração / ensino / estudo. Verbvm - Universidade Católica. Rio de Janeiro, t.15, 534-570, 1958.

FONSECA, Roberto Piragibe da. Programa e breviário de Propedêutica e de Metodologia da História. Verbvm - Universidade Católica. Rio de Janeiro, t.[11], 186-336, 1953.

FONSECA, Roberto Piragibe. Breviário de introdução a ciência do Direito: teoria geral do direito positivo. Rio de Janeiro: Olímpica, 1955. 
FREIRE, José Geraldes. Resenha de. JOSÉ VAN DEN BESSELAAR, António Vieira, História do Futuro (livro Anteprimeiro). Edição crítica, prefaciada e comentada. Vol.I, Bibliografia, introdução e texto, p282; Vol. II, Comentário, p263, Aschendorffsche Verlagsbuchhandlung, Münster Westfalen, 1976. Humanitas, Coimbra. v.29-30, 335-339, 1978. Disponível em <https://digitalisdsuc.pt/bitstream/10316.2/29343/2/Humanitas29-30_artigo54.pdf> Capturado em 5 mar. 2020.

FREITAS, Itamar. Discursos sobre o método em manuais de História (1870-1930). Porto Alegre, 2019. Tese (Doutorado em História) - Programa de Pós-Graduação em História; Universidade Federal do Rio Grande do Sul.

FREITAS, Itamar. Indícios de objetividade na Revista do IHGB: traços diacríticos da persona do historiador no Brasil (1880-1930). Fala. US São Paulo, 6 nov. 2015.

FUNDAÇÃO GETÚLIO VARGAS. Juraci Montenegro Magalhães nasceu em Fortaleza (1905-2001). Dicionário Histórico Biográfico Brasileiro pós 1930. $2^{\mathrm{a}}$ ed. Rio de Janeiro: Ed. FGV, 2001. Disponível em: < https://cpdoc.fgv.br/producao/dossies/AEraVargas1/biografias/juraci_magalhaes $>$ Capturado em: 04 fev. 2020.

GARI, Paul. Jean Glénisson. 2002/2006. Pollagoras - Site consacré aux ouvrages sur la Saintonge. Disponível em

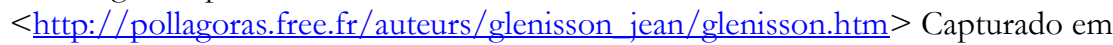
07 fev. 2020.

GLÉNISSON, Jean; CAMPOS, Pedro Moacyr; COSTA, Emília Viotti da. Iniciação aos estudos históricos. São Paulo: Difusão Europeia, 1961.

GURGEL, Walfredo. Parecer n.127, de 1963. Diário do Congresso Nacional. Brasília, 24 abr. 567-568, 1963.

HALPHEN, Louis. Introduction à l'histoire. Paris: Presses Universitaires de France, 1946. 53-57.

HARTMANN, Edouard. L'inconscient dans l'Histoire. In: Philosophie de l'inconscient. Paris: Germer Baillière, 1877. 410-439.

MARROU, Henri-Irénée. De la connaissance Historique. Paris: Seuil, 1954.

MEGILL, Allan. Teoria da História (1870-1940): objetividade e antinomias da história em um tempo de crise existencial. In: MALERBA, Jurandir (org.). Lições de História: da história científica à crítica da razão metódica no limiar do século XX. Porto Alegre; EDIPUCRS; Rio de Janeiro: FGV, 2013. 11-37.

NASCIMENTO, Thiago Rodrigues. A formação do professor de História no Brasil percurso histórico e periodização Revista História Hoje. São Paulo, v. 2, n. 4, 265 304, 2013.

OLIVEIRA, Krisley Aparecida de. José Honório Rodrigues e a Historiografia brasileira: em defesa de uma concepção de História. Goiânia, 2019. Dissertação (Mestrado em História) - Programa de Pós-Graduação em História - Universidade Federal de Goiás.

PIO X. Carta Encíclica Pascendi Dominici Gregis do Sumo Pontífice Pio X aos patriarcas, primazes, arcebispos, bispos e outros ordinários em paz e comunhão com a Sé Apostólica sobre as doutrinas modernistas. 1907. Disponível em: <http://www.montfort.org.br/bra/documentos/enciclicas/pascendi/> Capturado em: 23 jan. 2018.

REICHARDT, Herbert. Roberto Piragibe da Fonseca, Manual de Teoria da História Rio de Janeiro, 1970, Editora Fundo de Cultura. Revista do Instituto Histórico e Geográfico Brasileiro. Rio de Janeiro, v.301, 264-265, out./dez 1973. 
RODRIGUES, José Honório. Método, teoria, historiografia e pesquisa, disciplinas universitárias. In: Teoria da História do Brasil: introdução metodológica. 3ed. São Paulo: Companhia Editora nacional, 1969. 431-456.

ROIZ, Diogo da Silva. A institucionalização do ensino universitário de Geografia e História na Faculdade de Filosofia, Ciências e Letras da Universidade de São Paulo entre 1934 e 1956. Agora, Santa Cruz do Sul, v.13, n.1, 65-104. Disponível em: $<$ https://online.unisc.br/seer/index.php/agora/article/view/111/70> Capturado em: 06 fev. 2017.

SAAD, Cesar Leonardo Van Kan. Um teorista nos trópicos a escrita de Teoria da História do Brasil de José Honório Rodrigues (1939-1948). Porto Alegre, 2016. Dissertação (Mestrado em História) - Programa de Pós-Graduação em História, Universidade Federal do Rio Grande do Sul.

SANTO AGOSTINHO. A cidade de Deus. 2ed. Lisboa: Fundação Calouste Gulbenkian, 1996. v.1.

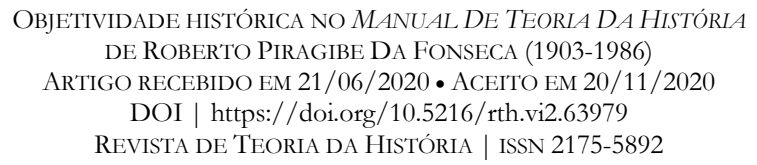

